\title{
A GRAMATICALIZAÇÃO DA LOCUÇÃO CONJUNTIVA POSTO QUE
}

Adriana Manolio (PUC-SP)

Resumo: Este artigo objetiva investigar o processo de gramaticalização que originou a locução conjuntiva subordinativa posto que. Assim, traça-se inicialmente uma breve introdução com a fundamentação teórica a respeito da gramaticalização e as diversas concepções concernentes a esse processo de mudança linguística. Em seguida, será investigado o processo histórico de gramaticalização do posto que e será analisada a trajetória do deslizamento de significado dessa locução, cujo valor semântico no português contemporâneo está sendo alterado de concessivo para causal. Afinal, verifica-se que, pelos dados analisados, a locução conjuntiva posto que originou-se de um processo de gramaticalização, bem como que ela está em trajetória de mudança semântica.

Palavras-chave: Gramaticalização; Locução conjuntiva; Posto que.

Abstract: This article aims to investigate the process of grammaticalization that originated the subordinative conjunctive locution "posto que" (although, even though). Thus, a brief introduction is initially outlined with the theoretical basis on grammaticalization and the various conceptions concerning this process of linguistic change. Next, the historical process of grammaticalization of "posto que" will be investigated and the trajectory of the sliding of meaning of this locution will be investigated, whose semantic value in contemporary Portuguese is being changed from concessive to causal. After all, it is verified that, because of the analyzed data, the conjunctive locution has originated from a process of grammaticalization, as well as that it is in a path of semantic change.

Keywords: Grammaticalization; Subordinative locution; Posto que.

\section{CONSIDERAÇÕES INICIAIS}

Este artigo tem como objetivo investigar o processo de gramaticalização que originou a locução conjuntiva posto que. 
Com base na concepção dinâmica do funcionamento das línguas, serão adotados neste trabalho os pressupostos teórico-metodológicos da linguística funcional, que preconiza a linguagem como um instrumento de interação social em que o uso da língua se adapta às necessidades comunicativas e cognitivas dos falantes.

Esta análise adota o princípio de que a gramaticalização se constitui em um processo unidirecional de mudança linguística que ocorre em determinados contextos, no qual o significado de itens lexicais passa do mais concreto para o menos concreto, resultando em expressões de funções mais abstratas, como se pretende demonstrar com o estudo do caso da locução posto que.

$\mathrm{O}$ artigo inicia-se com uma breve descrição histórica do paradigma da gramaticalização, também com a apresentação de alguns de seus princípios. Em seguida, será abordado o princípio da iconicidade, basilar para compreender a trajetória de mudança de significado segundo os pressupostos funcionalistas. Na sequência, será investigado o processo histórico de gramaticalização do posto que e será analisada a trajetória do deslizamento de significado dessa locução, cujo valor semântico no português contemporâneo está sendo alterado de concessivo para causal. 


\section{BREVE HISTÓRICO DA GRAMATICALIZAÇÃO}

De acordo com Gonçalves et al (2007), no final da década de 1980, o termo gramaticalização difundiu-se como paradigma para rotular esse fenômeno de mudança linguística. Os estudos de gramaticalização, conforme concebida hoje, surgem nas primeiras décadas do século $\mathrm{XX}$, tendo como figura central Antoine Meillet. Segundo Lehmann (1985, p.303 - tradução nossa), “o termo 'gramaticalização' foi usado primeiro por Meillet em um artigo de 1912 intitulado A evolução das formas gramaticais, no sentido de 'atribuição do caráter gramatical a uma palavra anteriormente autônoma'"'1.

Nos estudos pioneiros de Meillet, depreende-se, primeiramente, a ideia de gramaticalização como uma ferramenta da linguística histórica, que buscava dar conta das origens e das mudanças típicas envolvendo morfemas gramaticais, o que vinha a complementar o campo da etimologia e da evolução histórica das palavras.

De acordo com a acepção mais clássica de gramaticalização, palavras de uma categoria lexical plena (nomes, verbos e adjetivos) podem passar a integrar a classe das categorias gramaticais (preposições, conjunções, advérbios, auxiliares), as quais, em momento posterior, podem vir até mesmo a tornarse afixos.

1 'the term 'grammaticalization' was first used by A. Meillet in an article from 1912 entitled L'évolution des formes grammaticales, in the sense of 'attribution du caractère grammatical à un mot jadis autonome'"' (LEHMANN, 1985, p.303) 
Nas várias definições de gramaticalização percebe-se a preservação, em sua base, da definição clássica de Meillet. 0 enfoque da gramaticalização sofreu, entretanto, alargamento para incluir o estudo do itinerário percorrido por formas linguísticas e por construções gramaticais emergentes.

Kuryłowicz (1965), no seu artigo "The evolution of grammatical categories", propôs a seguinte definição: "gramaticalização consiste no aumento dos limites de um morfema que avança de um estado lexical para um gramatical ou de um estado menos gramatical para um mais gramatical, [...]"2 (Apud LEHMANN, 2015, p.7 - tradução nossa). Nessa definição, é introduzido o conceito de morfema no processo de gramaticalização e a mudança não somente de um item lexical para um gramatical, mas também a gradação de menos para mais gramatical.

Talmy Givón, em 1979, expande essa definição ao propor investigar o processo de gramaticalização partindo do discurso para morfossintaxe. Assim, o caráter historicista da gramaticalização passa a ser abordado de uma perspectiva sincrônica, concebida "como um fenômeno sintático, pragmático e discursivo, a ser investigado a partir dos padrões fluidos de uso da língua" (GONÇALVES et al, 2007, p.24).

2 "grammaticalization consists in the increase of the range of a morpheme advancing from a lexical to a grammatical or from a less grammatical to a more grammatical status, [...]"(KURYŁOWICZ, 1965 apud LEHMANN, 2015, p.7) 
De forma resumida, a evolução dos estudos de gramaticalização é representada como segue:

(i) a versão de Meillet, que concebe a gramaticalização como a passagem [+ lexical] > [- lexical];

(ii) a oferecida por Kurilowicz, que adiciona ao cline de Meillet a passagem [- gramatical] > [+ gramatical];

(iii) as versões dos estudos atuais [qualquer material linguístico]> [+gramatical]. (GONÇALVES et al, 2007, p.27)

É importante salientar que a diversidade de definições e termos ligados à gramaticalização demonstra que se trata de um paradigma teórico ainda em processo de construção. Neste artigo, o termo gramaticalização será usado no "sentido em que designa um processo unidirecional segundo o qual itens lexicais e construções sintáticas, em determinados contextos, passam a assumir funções gramaticais e, uma vez gramaticalizados, continuam a desenvolver novas funções gramaticais" (MARTELOTTA; VOTRE; CEZARIO, 1996, p.46).

No tocante aos princípios de gramaticalização, neste trabalho apresentamos os formulados por Paul Hopper, pois ressaltam o caráter gradual da gramaticalização. Para Hopper, a gramática de uma língua é sempre emergente, ou seja, estão sempre surgindo novas funções/valores/usos para formas já existentes. Nesse processo de emergência, 
é possível reconhecer graus variados de gramaticalização, a partir de padrões fluidos da linguagem. O autor propõe cinco parâmetros que permitem identificar os estágios desse processo de mudança: estratificação, divergência, especialização, persistência e descategorização. (GONÇALVES; CARVALHO, 2007, p.79)

De acordo com o princípio da estratificação, novas "camadas" emergem e coexistem com as antigas. Quando novas formas funcionais surgem, a substituição das equivalentes preexistentes não é imediata. A estratificação não surge para a eliminação das formas antigas e a substituição pelas novas formas; ela gera um "amontoamento" de formas diferenciadas que possuem, aproximadamente, o mesmo significado.

Segundo o princípio da divergência, uma unidade lexical que origina um processo de gramaticalização pode manter suas propriedades originais, preservando-se como item autônomo, sujeito a quaisquer mudanças inerentes a sua classe ou, até mesmo, passar por novo processo de gramaticalização. Esse princípio explica a existência de formas etimologicamente iguais, porém funcionalmente divergentes.

O princípio da especialização diz respeito à questão do estreitamento da escolha de formas pertencentes a um mesmo domínio. À medida que uma das formas começa 
a ocupar mais espaço, porque mais gramaticalizada, há um estreitamento de opções para codificar determinada função. O aumento na frequência de uso da forma mais gramaticalizada é uma consequência da especialização.

A manutenção de alguns traços semânticos da formafonte na forma gramaticalizada é prevista no princípio da persistência, o que pode gerar restrições sintáticas para o uso da forma gramaticalizada.

De acordo com o princípio da descategorização, a forma em gramaticalização tende a perder ou neutralizar as marcas morfológicas e a autonomia discursiva que caracterizam as formas plenas (como os verbos e nomes). Elas passam a assumir os atributos das categorias mais gramaticalizadas, tais como advérbios, pronomes, preposições e afixos.

\section{TRAJETÓRIA DE DESLIZAMENTO DO SIGNIFICADO}

A iconicidade é um dos princípios centrais da linguística funcional com orientação em Givón. Esse princípio prevê a existência de motivação na relação entre a forma e função, isto é, entre o código linguístico (expressão) e seu significado (conteúdo). Isso implica que, sendo a linguagem uma faculdade humana, "a suposição geral é a de que a estrutura linguística revela o funcionamento da mente, bem como as propriedades da conceitualização humana 
do mundo". Os estudos sobre os processos de variação e mudança linguística, no entanto, revelam "muitos casos em que não há uma relação clara, transparente, entre expressão e conteúdo". São casos nos quais o significado original do elemento linguístico se perdeu total ou parcialmente, assim como a motivação para sua criação. A explicação está relacionada ao fato de que, em contextos comunicativos, "a iconicidade do código linguístico está sujeita a pressões diacrônicas corrosivas tanto na forma quanto na função" através de processos metafóricos e metonímicos, os quais serão abordados adiante neste artigo (CUNHA, 2012, p.167).

Respeitando o princípio da iconicidade, os estudos da gramaticalização apresentam duas propostas de trajetória de mudança, ambas postulando a abstralização progressiva do significado. (VOTRE, 1996) A primeira consiste na proposta de trajetória de deslizamento do significado, formulada originalmente por Traugott, segundo a qual:

[...] as formas associam-se a novos significados, progressivamente mais abstratos, partindo da noção de espaço, podendo passar ou não pela noção de tempo, e desembocando na categoria mais abstrata de texto, conforme se vê no esquema seguinte: espaço > (tempo) $>$ texto. (VOTRE, 1996, p.33)

A segunda proposta é apresentada por Heine: corpo > objeto > processo > espaço > tempo > qualificação. 
Essa escala demonstra que a gramaticalização tende a se processar em um crescente de abstraticidade, partindo do corpo humano como fonte natural do processo metafórico até atingir a ideia de qualificação (próxima da ideia de texto em Traugott).

De acordo ainda com os funcionalistas de orientação givoniana, as línguas possuem um sistema semântico cognitivo de base experimental, que opera e determina as regularidades que caracterizam a derivação dos sentidos através da transferência do mundo real para os domínios do mundo abstrato.

Os mecanismos que geram as mudanças por gramaticalização podem ser de natureza metafórica e de natureza metonímica, conforme citado anteriormente:

A metáfora constitui um processo unidirecional de abstralização crescente, pelo qual conceitos que estão próximos da experiência humana são utilizados para expressar aquilo que é mais abstrato e, consequentemente, mais difícil de ser definido. A metonímia diz respeito aos processos de mudança por contiguidade, no sentido de que são gerados no contexto sintático. (MARTELOTTA; VOTRE; CEZARIO, 1996, p.54)

É por meio da transferência metafórica, proposta por Heine, que ocorre o deslizamento semântico que gera 
novos significados. O processo de transferência metafórica fundamenta-se em algum tipo de semelhança entre o significado (já associado a uma forma), e um novo significado.

Já o processo da metonímia designa a mudança que uma determinada forma sofre em função do contexto linguístico em que está sendo empregada. A mudança não ocorre somente na forma em si, mas também na expressão toda da qual faz parte, em razão da contiguidade posicional ou sintática.

Outro mecanismo relacionado ao processo metonímico é a chamada "inferência por pressão de informatividade", proposta por Traugott e König (MARTELOTTA; VOTRE; CEZARIO, 1996). A pressão de informatividade é um processo em que o elemento linguístico assume um novo valor, que emerge de determinados contextos nos quais o novo significado pode serinferido do primeiro, independentemente do valor textual das cláusulas envolvidas no processo. Esse mecanismo predomina na gramaticalização de operadores argumentativos.

\section{GRAMATICALIZAÇÃO DA LOCUÇÃO CONJUNTIVA POSTO QUE}

Nesta seção será analisado o processo históricodiacrônico que levou ao surgimento da locução conjuntiva posto que, a partir do princípio de que a formação dessa 
locução foi consequência de uma trajetória de mudança por gramaticalização espaço > (tempo) > texto.

Ensina Câmara Jr. (1976) que o vocábulo posto é proveniente da forma latina positu-, particípio passado do verbo ponẽre (pôr), que persistiu no português moderno. Era próprio do verbo em latim a existência de formas verbais de estrutura nominal, entre elas os "particípios", sob a forma de adjetivos: "um presente, que era um adjetivo de tema em -e; um pretérito, de aspecto concluso, que era um adjetivo de tema $u / o$; e, ainda de tema em $u / o$, um particípio futuro" (CÂMARA Jr., 1976, p.126).

Da forma latina original, surge a forma abreviada postus, cujo significado estava relacionado com o sentido espacial de lugar onde se acha colocada uma pessoa ou uma coisa (CUNHA, 2010, p.514). Constata-se, assim, a trajetória de valor espacial para temporal, assumido pelo particípio passado já no latim. Ao unir-se com a partícula que, a trajetória do elemento posto se completa, assumindo valor textual, como será visto a seguir.

Said Ali (1971, p.220) assevera que a origem de certas conjunções latinas é obscura: "da respeitável série de conjunções que faziam parte do idioma latino muito poucas passaram às línguas românicas".

Nesse mesmo sentido, segundo Câmara Jr. (1976), no português houve uma remodelação profunda do quadro 
das conjunções subordinativas em relação à tradição latina. O aparecimento da partícula que como conjunção subordinativa foi o fato primordial. Como índice básico da subordinação oracional, o que entra em aglutinações (ex.: porque) ou figura como parte final de perífrases, ou locuções, conjuncionais subordinativas.

É a partir da combinação do particípio posto com a partícula que, que foi criada a locução conjuntiva posto que, conforme ensinamento de Said Ali:

Serve a oração integrante de objeto a dado, posto, admitido e outros particípios usados como o ablativo absoluto em latim, para expressar concessão, hipótese, etc. Perdura nestes particípios geralmente o sentido próprio do verbo; posto entretanto ligou-se semanticamente à partícula, produzindo a conjunção concessiva posto que. (1971, p.222)

Por meio dessa descrição do surgimento da locução posto que, constata-se que houve um processo de gramaticalização, no qual o elemento posto foi deslocado do sentido próprio original do verbo, emigrando de sua respectiva oração, atraído pela conjunção que, à qual se uniu para, semanticamente, formar uma nova espécie de conjunção. Percebe-se, assim, um processo metonímico em que, por contiguidade, houve uma mudança determinada em função do contexto linguístico. 
Consoante observa Bechara:

[...] diversos particípios fixos no masculino singular se unem a orações transpostas mediante que, dando origem a transpositores complexos de orações adverbias, do tipo de dado que, posto que, visto que, suposto que, salvo que, exceto que, não obstante que: [...]. (2009, p.473 - grifo nosso)

Bechara (2009) prossegue explicando que, primitivamente, o que introduzia oração com a função de sujeito do particípio, o que explica estar o particípio no masculino singular, pois uma oração definida materialmente é considerada do gênero masculino e do número singular.

A partir desta explicação do autor, verifica-se que ao assumir a categoria mais gramaticalizada de locução conjuntiva, o particípio posto teve neutralizadas suas marcas morfológicas e perdeu sua autonomia discursiva, que caracterizavam a forma plena verbal. Portanto, aplica-se ao caso de gramaticalização do posto que o princípio da descategorização.

Outro princípio que se aplica ao caso da gramaticalização do posto que é o da divergência, tendo em vista que a unidade lexical posto, que deu origem ao processo de gramaticalização, manteve-se como item autônomo, sendo ainda empregada como particípio do verbo pôr. Esse princípio explica a coexistência de formas etimologicamente iguais, porém com funcionamento divergente. 


\section{DESLOCAMENTO DE SIGNIFICADO DO POSTO QUE}

Tradicionalmente, a locução conjuntiva posto que é definida como uma perífrase que introduz uma oração subordinada concessiva em que se admite um fato contrário à ação principal, mas incapaz de impedi-la (CUNHA; CINTRA, 2008, p.600). No entanto, no português contemporâneo tem sido registrado o emprego do posto que como conectivo causal, conforme aponta Houaiss (2009, p.1532): “GRAM/ USO o emprego de $p$. que como causal, corrente no Brasil, é rejeitado pelos gramáticos".

As primeiras ocorrências da locução conjuntiva posto que no português já se verificam nos séculos XIV e XV. Do final do século XIV, há o exemplo extraído da obra Orto do esposo, texto cujo manuscrito se encontra na Biblioteca Nacional de Lisboa (CUNHA, 2014, p.2041):

(1) [...] e dise-Ihe Sancto Ignacio: Posto que me talhes a lingua, nõ cessarey porem de chamar o nome de Jhesu [...].

Das ocorrências descritas no século XV, apresenta-se a seguir dois exemplos do uso da locução conjuntiva posto que:

(2) Guardate quanto poderes da companhia e grande conversaçom dos homẽes, porque muito embarga ao rreligioso o trauto e a fazenda dos fectos secullares, posto que se façam com simprez boa entençõ [...]. ${ }^{3}$

3 Exemplo original do texto A linguagem da Imitação de Cristo, versão portuguesa de Fr. João Alvares Lisboa. 
(3) [...] tall que estando acerca de muitos homẽes, posto que conhecido não fosse, logo o julgariam por rrei dos outros. ${ }^{4}$ (CUNHA, 2014, p.2041)

Parafraseada, nos três exemplos anteriores, a locução conjuntiva posto que pela conjunção concessiva embora, verifica-se que a locução, nesses casos do português arcaico, é empregada em posição inicial na oração que exprime o valor de concessão.

Nos textos das chamadas Ordenações Filipinas, editadas em 1603 e vigentes por mais de três séculos - no Brasil, só deixaram de vigorar com a promulgação do Código Civil de 1916-, diversas ocorrências da locução conjuntiva posto que são encontradas, sempre com valor concessivo (ORDENAÇÕES, 1747):

(4) Ajuntamento de gente, quem o fizer naõ entrando em casa, posto que naõ faça mal, se for Fidalgo, he degrado por quatro anos para Africa, e paga cem cruzados. (p.28)

(5) Hey por bem, e me praz de declarar, que qualquer pessoa, que for promovida de hum officio a outro, ha de largar o que d'antes tinha, posto que sejão compatíveis, se eu logo não declarar o contrario. (p.405)

Passando para o século XVIII, as ocorrências da locução conjuntiva posto que também são encontradas com valor concessivo nas leis complementares das Ordenações Filipinas (COLLEÇÃO, 1828):

4 Exemplo original do texto de Fernão Lopes, Crônica del rei dom Joham I de boa memória e dos reis de Portugal o décimo. Reprodução fac-similada da edição do Arquivo Histórico Português. 
(6) [...] e estes Officiaes devão ser Pessoas de zelo, fidelidade, e intelligencia na escrituração dos livros, em fórma que as Receitas, posto que lançadas pelo Escrivão, hajão de ser com methodo, e regularidade, que emende as confusões, que até agora houve: [...]. (p.78)

(7) E este se cumprirá como nelle se contém, e valerá como Carta passada pela Chancellaria, posto que por ella não ha de passar, e que o seu effeito haja de durar mais de hum anno, sem embargo das Ordenações, [...]. (p.82)

Já no século XIX, em trabalho de compilação das decisões proferidas por juízes no Tribunal Civil e Criminal (MONTENEGRO, 1895), prosseguem as ocorrências da locução conjuntiva posto que com valor concessivo:

(8) [...] e posto que inventario e balanço sejam uma mesma cousa, no dizer de Ferreira Borges (Dicc. Jur. Comm.), o art. 174 faz distincção, mandando proceder a um e outro; [...]. (p.357)

(9) [...] em vista da clara disposição do art. 236 do Codigo Commercial: O que der a fabricar alguma obra de empreitada poderá a seu arbitrio rescindir o contracto, posto que a obra já esteja começada a executar, indemnisando o empreiteiro de todas as despezas e trabalhos e de tudo que poderia ganhar na mesma obra. (p.389)

O valor concessivo de posto que persiste no início do século XX, conforme demonstram os exemplos abaixo:

(10) É indispensável recordar, posto que ligeiramente, alguns conceitos elementares, cujo esquecimento deu em resultado o facto que originou este processo e a presente decisão. (CASTRO, 1925, p.688) 
(11) Art. 825. São susceptíveis do contrato de hipoteca os navios, posto que ainda em construção. (CÓDIGO CIVIL, 1916)

Percorrida essa trajetória histórica da locução conjuntiva posto que, mesmo que de forma breve, percebe-se que o valor concessivo da perífrase se manteve desde o português arcaico até o português moderno.

Desta forma, é classificada essa locução nas gramáticas tradicionais que seguem sendo editadas no Brasil: "CONCESSIVAS: quando iniciam oração que exprime um obstáculo - real ou suposto - não impedirá ou modificará a declaração da oração principal: ainda que, embora, posto que, se bem que, apesar de que, etc" (BECHARA, 2009, p.327); "CONCESSIVAS (iniciam uma oração subordinada em que se admite um fato contrário à ação principal, mas incapaz de impedi-la): embora, conquanto, ainda que, mesmo que, posto que, [...]" (CUNHA; CINTRA, 2008, p.600); "CONCESSIVAS: Embora, conquanto, ainda que, posto que, se bem que, etc. [...] A oração concessiva expressa um fato - real, ou suposto - que poderia opor-se à realização de outro fato principal, porém não frustrará o cumprimento deste" (ROCHA LIMA, 2012, p.344).

Mesmo nas gramáticas de base funcionalista, o posto que é rotulado como concessivo. Ao elencar as locuções conjuntivas 
concessivas em sua Gramática de usos do português, Neves (2000) inclui entre elas o "posto que" e exemplifica: "'Saber português' e 'saber gramática', duas capacidades diferentes, POSTO QUE extremamente conexas" (p.863).

Entretanto, Neves observa que as construções concessivas expressam, de certo modo, uma conexão "causal" entendida num sentido amplo: "no sentido geral, o que ocorre numa construção concessiva é que uma pretensa causa (ou uma condição) é expressa na oração concessiva, mas aquilo que dela se pode esperar é negado na oração principal". (2000, p.868 - grifos da autora)

Também o Dicionário de usos do Português do Brasil aponta o emprego da locução conjuntiva posto que somente como introdutória de oração adverbial concessiva (BORBA, 2002, p.1244). Na obra de Castilho (2010), Nova gramática do português brasileiro, o caso da locução conjuntiva posto que não é abordado.

É apenas na obra de Azeredo (2014) que surge o posto que citado como uma locução conjuntiva que tem sido empregada com sentido causal. Essa informação, entretanto, aparece como um adendo dentro do item dedicado às orações que expressam "contraste", distinguindo o autor entre o contraste adversativo e o concessivo. Explica Azeredo, ao tratar das conjunções não obstante, nada obstante, conquanto, posto que: 
Significam o mesmo que embora, mas são expressões conetivas praticamente restritas a usos acadêmicos formais, como os discursos solenes e os textos jurídicos. Os dois primeiros são advérbios conjuntivos. Os dois últimos são conjunções subordinativas adverbiais. Um detalhe, porém, é notável: é cada vez mais comum na variedade escrita contemporânea o emprego de posto que com valor causal, haja vista o célebre verso do "Soneto de Fidelidade", de Vinicius de Moraes: "Que não seja imortal, posto que [= já que] é chama". (2014, p.335 - grifo nosso)

Em sua tese de doutorado sobre a gramaticalização de conectores causais, Amorim propõe, a respeito do emprego inovador de posto que, "[ser] possível que entre posto que concessivo e sua variante causal não exista uma relação derivativa: a mudança pode estar relacionada a outros correlatos contextuais, e não a um processo inferencial entre concessão e causa" (2017, p.178).

Outra hipótese levantada no trabalho de Amorim (2017), seria que o surgimento do sentido causal de posto que estaria ligado ao fato de ele se conectar a orações com verbo no indicativo, o que é bastante incomum no seu uso concessivo. No corpus do seu trabalho, o pesquisador afirma ter encontrado respaldo, "uma vez que a particularidade do emprego causal desse conector é justamente o fato de ele 
introduzir orações com verbo no indicativo, diferentemente do uso como concessivo, seguido categoricamente de segmentos com verbo no subjuntivo". (p.179).

Tendo em vista os limites deste artigo, a verificação dessa hipótese, de que o deslizamento semântico do posto que para causal estaria atrelado às orações com verbo no indicativo, extrapola o objetivo do presente estudo. No entanto, para futuros trabalhos, propõe-se o levantamento das ocorrências do posto que tendo como corpus o Diário Oficial do Estado de São Paulo (DOESP), cujas publicações desde a década de 1890 estão disponíveis on-line, a fim de ratificar a verificação dessa hipótese por meio da língua em uso.

Em pesquisa no site do DOESP sobre a quantidade de ocorrências da locução conjuntiva posto que, constatou-se os seguintes números:

\begin{tabular}{|c|c|}
\hline Década da Publicação & № Ocorrências \\
\hline 1890 & 73 \\
\hline 1900 & 40 \\
\hline 1910 & 12 \\
\hline 1920 & 48 \\
\hline 1930 & 379 \\
\hline 1940 & 447 \\
\hline 1950 & 981 \\
\hline 1960 & 1.918 \\
\hline 1970 & 4.060 \\
\hline
\end{tabular}




\begin{tabular}{|c|c|}
\hline Década da Publicação & № Ocorrências \\
\hline 1980 & 19.354 \\
\hline 1990 & 57.037 \\
\hline 2000 & 564.263 \\
\hline 2010 & 932.433 \\
\hline
\end{tabular}

Quadro 1 - Número de ocorrências de posto que no DOESP (Fonte: própria autora)

Percebe-se pelo quadro 1 que o número de ocorrências do posto que é expressiva nos textos do Diário Oficial, veículo em que predomina a linguagem formal da redação oficial e do discurso jurídico. Seguem abaixo exemplos de usos da locução conjuntiva posto que, retirados do corpus do DOESP, cujo significado é causal:

(12) Vereador Imero Silva: Tem razão V. Exa, em aditamento ao seu brilhante aparte, que muito agradeço, seria de se afirmar que esse movimento modernista é o único que assume importância entre nós atualmente e não só entre nós como em todo o mundo, posto que ao verificar que brilhantes escritores de nossos dias estão filiados ao movimento a que V. Exa. aludiu. (DOESP, 11 fev., 1953, p.41)

(13) [...] entende a diretoria ser aconselhável a transformação da sociedade, de anônima em civil por quotas de responsabilidade limitada, posto que as despesas poderão ser reduzidas, [...]. (DOESP, 13 set., 1969, p.49)

(14) Na petição de fls. 263 da autora este Juízo não entendeu a redação, com a introdução da conjunção concessiva "posto que", que alguns vem usando como conjunção causal,[...]. (DOESP, 19 dez., 1973, p.52)

Conforme afirma Azeredo, o emprego do posto que está relacionado, principalmente, com o discurso do domínio 
jurídico. Destaca-se, inclusive, no exemplo 14, a observação do juiz sobre o "erro" de interpretação resultante do uso do posto que como locução causal. Portanto, o estudo aprofundado das ocorrências no jornal DOESP, que publica as decisões dos poderes judiciário, legislativo e executivo paulista, seria uma excelente oportunidade de levantar os dados relativos à trajetória de deslizamento do significado do posto que.

\section{CONSIDERAÇÕES FINAIS}

O estudo do processo de constituição da locução conjuntiva posto que revelou que sua trajetória de gramaticalicação caracterizou-se por um caráter gradual e unidirecional, de forma plena para a mais gramatical, em que o vocábulo posto, originalmente particípio passado do verbo pôr, foi deslocado do seu sentido próprio original de forma nominal de verbo, atraído pela conjunção que, à qual se uniu para, semanticamente, formar uma nova espécie de conjunção, por meio de um processo metonímico.

Concluiu-se também que a tradição gramatical o classifica como locução conjuntiva concessiva, assim como ainda alguns estudiosos da gramática funcional, valor presente desde o português arcaico. Entretanto, gradativamente, a locução posto que sofreu transformações semânticas, 
provavelmente em função da pressão de determinados tipos de contextos sintáticos, passando a estabelecer uma conexão causal entre a oração principal e a subordinada, tornando-se comum, hoje, no Brasil, seu uso como locução conjuntiva causal.

\section{REFERÊNCIAS}

AMORIM, Fabrício da Silva (2017). Gramaticalização de conectores causais na história do português. 212f. (Tese - Doutorado em Estudos Linguísticos), Universidade Estadual Paulista, São José do Rio Preto. In https:// repositorio.unesp.br/handle/11449/150717. Acesso em 17.Nov.2017.

AZEREDO, José Carlos de (2014). Gramática Houaiss da língua portuguesa. 3.ed. São Paulo: Publifolha.

BECHARA, Evanildo (2009). Moderna gramática portuguesa. 37.ed. Rio de Janeiro: Nova Fronteira.

BORBA, Francisco S (2002). Dicionário de usos do Português do Brasil. São Paulo: Ática.

CÂMARA JR., Joaquim Mattoso (1976). História e estrutura da língua portuguesa. 2.ed. Rio de Janeiro: Padrão.

Lisboa: Na Typografia Maigrense (1828). COLLECÇÃO da legislação portugueza: desde a ultima compilação das ordenações. v.1. Legislação de 1775 a 1790. In http://www2.senado.leg.br/bdsf/handle/id/518674 Acesso em 17.Nov.2017.

CUNHA, Angélica Furtado da (2012). Funcionalismo. In: MARTELOTTA, Mário Eduardo (Org.) Manual de linguística. São Paulo: Contexto, p.157176.

CUNHA, Antônio Geraldo da (2010). Dicionário etimológico da língua portuguesa. Rio de Janeiro: Lexikon.

(2014). Vocabulário histórico-cronológico do Português medieval.

2 v. Rio de Janeiro: Fundação Casa de Rui Barbosa. 
CUNHA, Celso; CINTRA, Lindley (2008). Nova gramática do português contemporâneo. 5.ed. Rio de Janeiro: Lexikon.

DIÁRIO OFICIAL DO ESTADO DE SÃO PAULO. In https://www. imprensaoficial.com.br. Acesso em 17.Nov.2017.

GONÇALVES, Sebastião Carlos Leite et al (2007). "Tratado geral sobre gramaticalização". In: GONÇALVES, Sebastião Carlos Leite; LIMAHERNANDES, Maria Célia; CASSEB-GALVÃO, Vânia Cristina (Orgs.) Introdução à gramaticalização: princípios teóricos \& aplicação. São Paulo: Parábola, p.15-27.

; CARVALHO, Cristina dos Santos (2007). "Critérios de gramaticalização". In: GONÇALVES, Sebastião Carlos Leite; LIMAHERNANDES, Maria Célia; CASSEB-GALVÃO, Vânia Cristina. (Orgs.) Introdução à gramaticalização: princípios teóricos \& aplicação. São Paulo: Parábola, p.67-90.

HOUAISS, Antonio (2009). Dicionário Houaiss da língua portuguesa. Rio de Janeiro: Objetiva.

LEHMANN, Christian (1985). "Grammaticalization: synchronic variation and diachronic change". Lingua e Stile, n.20, p.303-318. In http://www. christianlehmann.eu/publ/syn_dia.pdf Acesso em 25.Nov.2017

(2015). Thoughts on grammaticalization. 3rd ed. Berlin: Language

Science Press. In http://langsci-press.org//catalog/view/88/98/344-1 Acesso em 25.Nov.2017.

MARTELOTTA, Mário Eduardo; VOTRE, Sebastião Josué; CEZARIO, Maria Maura (1996). "O paradigma da gramaticalização". In: (Orgs.) Gramaticalização no português do Brasil: uma abordagem funcional. Rio de Janeiro: Tempo Brasileiro, p.45-75.

MONTENEgRO, Caetano Pinto de Miranda (1895). Trabalhos judiciarios. Rio de Janeiro: Imprensa Nacional. In http://www2.senado.gov.br/bdsf/ handle/id/520863 Acesso em 17.Nov.2017.

NEVES, Maria Helena de Moura (2000). Gramática de usos do português. São Paulo: Editora UNESP. 
Lisboa: No Mosteiro de S. Vicente de Fóra, Camara Real de sua Magestade (1747). ORDENAÇÕES, e Leys do Reyno de Portugal, confirmadas, e estabelecida pelo Senhor Rey D. João IV. In http://www2.senado.leg.br/ bdsf/handle/id/242788 Acesso em 17.Nov.2017.

ROCHA LIMA, Carlos Henrique da (2012). Gramática normativa da língua portuguesa. 50. ed. Rio de Janeiro: José Olympio.

SAID ALI, Manuel (1971). Gramática histórica da língua portuguesa. 7.ed. Rio de Janeiro: Melhoramentos.

VIVEIROS, Castro. Accordams e votos: commentados. Rio de Janeiro: Typ. da Revista do Supremo Trigunal, 1925. Disponível em http://www.stf.jus. br/bibliotecadigital/DominioPublico/43663/pdf/43663.pdf Acesso em 17 Nov.2017.

VOTRE, Sebastião Josué (1996). “Um paradigma para a linguística funcional". In: MARTELOTTA, Mário Eduardo; VOTRE, Sebastião Josué; CEZARIO, Maria Maura (Orgs.) Gramaticalização no português do Brasil: uma abordagem funcional. Rio de Janeiro: Tempo Brasileiro, p.27-43.

Adriana Manolio é Mestranda em Língua Portuguesa, PUC-SP, bolsista CAPES, integrante do grupo de estudo História das ideias linguísticas (Brasil e Portugal) e identidade nacional. E-mail: manolioadriana@gmail. com 